\title{
Violência ocupacional na Enfermagem
}

\author{
Occupational Violence in Nursing \\ Violencia ocupacional en enfermería
}

Recebido: 16/06/2021 | Revisado: 19/06/2021 | Aceito: 19/06/2021 | Publicado: 30/06/2021

\author{
Brenner Saboia Martins \\ ORCID: https://orcid.org/0000-0001-5053-3559 \\ Universidade Paulista, Brasil \\ E-mail: Brennersaboia@hotmail.com \\ Mayara Cândida Pereira \\ ORCID: https://orcid.org/0000-0002-0242-6262 \\ Universidade Paulista, Brasil \\ E-mail: mayara.pereira@docente.unip.br
}

\begin{abstract}
Resumo
Objetivo: Descrever sobre a violência ocupacional entre os profissionais de enfermagem. Metodologia: Trata-se de um estudo exploratório e descritivo, realizado por meio de uma revisão integrativa da literatura, utilizando o método de pesquisa bibliográfica, por meio de buscas em bases de dados virtuais como o Sistema Latino-Americano e do Caribe de informação em Ciências da Saúde (LILACS), Scientific Electronic Library Online (SciELO), Banco de Teses da UFC, bem como outros periódicos publicados na Revista Acervo Saúde e Brazilian Journal of Health Review, entre os anos 2014 a 2021. Resultados: Os resultados encontrados sugerem que os tipos mais comuns de violência no trabalho são: agressão física, abuso verbal, assédio moral, assédio sexual e também a discriminação racial. Os profissionais da enfermagem enxergam a violência ocupacional como fator negativo e preocupante, pois não recebem estímulos da Instituição para o relato e tomada de medidas mais rígidas. Visto que a violência pode trazer complicações aos aspectos globais de desenvolvimento do indivíduo. Conclusão: A violência ocupacional que acomete os profissionais da enfermagem desordena profundamente a integridade física, emocional, moral e social. E isso não ocorre somente dentro da Instituição, em seu horário de trabalho. É um fato que acompanha o trabalhador em sua vida diária. Foi possível observar que a violência física é a mais comum entre os colegas de trabalho, seguida da agressão verbal. Ademais, fica evidente que condutas de prevenção e controle da violência no trabalho foram objetos de estudo de poucas produções científicas pesquisadas.
\end{abstract}

Palavras-chave: Enfermagem; Saúde do trabalhador; Violência ocupacional.

\begin{abstract}
Objective: To describe occupational violence among nursing professionals. Methodology: This is an exploratory and descriptive study, carried out through an integrative literature review, using the bibliographic research method, through searches in virtual databases such as the Latin American and Caribbean Information System in Health Sciences (LILACS), Scientific Electronic Library Online (SciELO), UFC Theses Bank, as well as other periodicals published in Revista Acervo Saúde and Revista Brasileira de Saúde, between 2014 and 2021. Results: The results found. that the most common types of violence at work are: physical aggression, verbal abuse, moral harassment, sexual harassment and also racial discrimination. Nursing professionals see occupational violence as a negative and worrisome factor, as they do not encourage the institution to report and take stricter measures. Since violence can bring complications to the individual's overall developmental aspects. Conclusion: Occupational violence that affects nursing professionals profoundly disrupts the physical, emotional, moral and social integrity. And this does not only occur within the institution, during its working hours. It is a fact that accompanies the worker in his daily life. It was possible to observe that physical violence is the most common among co-workers, after verbal aggression. Furthermore, it is evident that behaviors for the prevention and control of violence at work were objects of study in billions of researched scientific productions.
\end{abstract}

Keywords: Occupational violence; Infirmary; Worker's health.

\section{Resumen}

Objetivo: Describir la violencia laboral entre profesionales de enfermería. Metodología: Se trata de un estudio exploratorio y descriptivo, realizado a través de una revisión integradora de la literatura, utilizando el método de investigación bibliográfica, mediante búsquedas en bases de datos virtuales como el Sistema de Información de América Latina y el Caribe en Ciencias de la Salud (LILACS), Scientific Electronic Library Online ( SciELO), UFC Theses Bank, así como otras publicaciones periódicas publicadas en Revista Acervo Saúde y Revista Brasileira de Saúde, entre 2014 y 2021. Resultados: Los resultados encontrados. que los tipos de violencia más comunes en el 
trabajo son: agresión física, abuso verbal, acoso moral, acoso sexual y también discriminación racial. Los profesionales de enfermería ven la violencia laboral como un factor negativo y preocupante, ya que no incitan a la institución a denunciar y tomar medidas más estrictas. Dado que la violencia puede traer complicaciones a los aspectos generales del desarrollo del individuo. Conclusión: La violencia laboral que afecta a los profesionales de enfermería altera profundamente la integridad física, emocional, moral y social. Y esto no solo ocurre dentro de la institución, durante su horario laboral. Es un hecho que acompaña al trabajador en su vida diaria. Se pudo observar que la violencia física es la más común entre compañeros de trabajo, luego de la agresión verbal. Además, es evidente que las conductas para la prevención y el control de la violencia en el trabajo fueron objeto de estudio en miles de millones de producciones científicas investigadas.

Palabras clave: Violencia ocupacional; Enfermería; Salud del trabajador.

\section{Introdução}

A violência é um problema da saúde que sempre esteve presente na sociedade, sendo reconhecida mundialmente como um contratempo de difícil enfrentamento. Este é um problema, por vezes coletivo ou individual, que em sua maioria ocasionam danos físicos e mentais.

O número de trabalhadores atingidos pela violência é expressivo, causando impacto na vida da população, bem como por extensão, no setor da saúde. Ela é um risco para a integridade dos seres humanos, pois, ameaça a vida, altera a saúde e produz enfermidades. (Amorim et al., 2021)

Além disso, a violência contra os profissionais da área da saúde extrapola as agressões e ofensas individuais, colocando em risco a qualidade do cuidado e a produtividade no trabalho dentro da Instituição. (Amorim et al., 2021)

Assim, a Organização Mundial de Saúde (OMS) (2002), define a violência como sendo o uso intencional da força física ou do poder, real ou em ameaça, contra si próprio, contra outra pessoa, contra um grupo ou uma comunidade, que resulte ou tenha grande possibilidade de resultar em lesão, morte, dano psicológico, deficiência de desenvolvimento ou privação.

De acordo com o Ministério do Trabalho (2004), a violência associada ao trabalho é um problema mundial e tem sido estudada em suas múltiplas particularidades. Entre os temas de estudo estão: a violência contra o trabalhador no seu local de trabalho; a violência oriunda de relações profissionais deterioradas; a violência ligada ao assédio moral, caracterizado pelas agressões entre pares, chefias e subordinados.

Para a OMS (2002) a violência ocupacional é definida como situações onde o trabalhador sofre abuso, ameaça ou ataque em circunstâncias relacionadas ao seu labor, incluindo o trajeto de ida e volta, envolvendo ameaça explícita ou implícita para sua segurança, bem-estar ou saúde.

Nesse sentido, o Código de Ética dos Profissionais de Enfermagem dispõe sobre proibições inerentes aos profissionais e estabelece em seu Art. 34 que é proibido provocar, cooperar, ser conivente ou omisso com qualquer forma de violência. (Conselho Federal de Enfermagem, 2017)

Para tanto, a motivação para a pesquisa e elaboração deste estudo surgiu dos grandes números de trabalhos na literatura sobre a violência na equipe de enfermagem. Para responder a esta questão, foi delineado o objetivo geral que é descrever sobre a violência ocupacional com os profissionais de enfermagem. Como objetivos específicos: identificar os tipos e os motivos mais comuns relacionados à violência entre a equipe de enfermagem, violência ocupacional entre os profissionais de enfermagem e consequências decorrentes da violência ocupacional.

\section{Metodologia}

Para o presente estudo optou-se por um estudo exploratório e descritivo, realizado por meio de uma revisão integrativa da literatura, utilizando o método de pesquisa bibliográfica. De acordo com Marconi e Lakatos (2017), esse tipo de pesquisa não é mera repetição do que já foi dito ou escrito sobre certo assunto, mas propicia o exame de um tema sob novo enfoque ou 
abordagem, chegando a conclusões inovadoras (p. 189).

Quanto aos aspectos metodológicos, a coleta de dados se deu por meio de buscas em bases de dados virtuais em saúde especificamente no Sistema Latino-Americano e do Caribe de informação em Ciências da Saúde (LILACS), Scientific Electronic Library Online (SciELO), Publisher e Banco de Teses UFC, bem como outros periódicos publicados na Revista Acervo Saúde e Brazilian Journal of Health Review. Para a busca foram utilizados os seguintes descritores: violência ocupacional, enfermagem, saúde do trabalhador.

As buscas nas bases de dados resultaram na coleta de 115 artigos, sendo que 59 foram na base SciELO, 52 na base LILACS, 01 no Banco de Teses UFC e 03 em outros periódicos. Os estudos que atenderam ao critério de inclusão foram 29. Contudo, 15 deles foram excluídos após a etapa do critério de exclusão. Então, 14 artigos foram selecionados para serem objetos de estudo nesta pesquisa.

Os critérios de inclusão estabelecidos são artigos originais disponibilizados na íntegra e na forma online, publicados na língua portuguesa, no período compreendido entre os anos de 2014 a 2021.

Quanto aos critérios de exclusão, foram artigos que foram publicados antes do ano 2013 e que não correspondiam aos objetivos do trabalho. Para o desenvolvimento do trabalho serão utilizados 14 artigos entre os anos de 2014 a 2021.

A análise dos dados se deu por meio da investigação dos estudos que abordavam sobre a temática escolhida, buscando compreender os principais fatores envolvidos na violência ocupacional com a equipe de enfermagem, e descreve-los.

\section{Resultados e Discussão}

No Quadro 1 a seguir, está descrito o tema de cada estudo selecionado, os autores, o método, a conclusão, bem como o ano de publicação e o objetivo de cada estudo. Esses artigos serão utilizados para descrever dar embasamento teórico a esta pesquisa.

Quadro 1: Distribuição dos artigos de acordo com o título, autores, objetivo, método, e ano de publicação.

\begin{tabular}{|c|c|c|c|c|c|c|}
\hline & Título & & Autor/ano & Objetivos & Metodologia & Conclusão \\
\hline 雨 & $\begin{array}{l}\text { Violência } \\
\text { trabalho } \\
\text { perspectiva } \\
\text { profissionais } \\
\text { enfermagem. }\end{array}$ & $\begin{array}{l}\text { no } \\
\text { na } \\
\text { de } \\
\text { de }\end{array}$ & 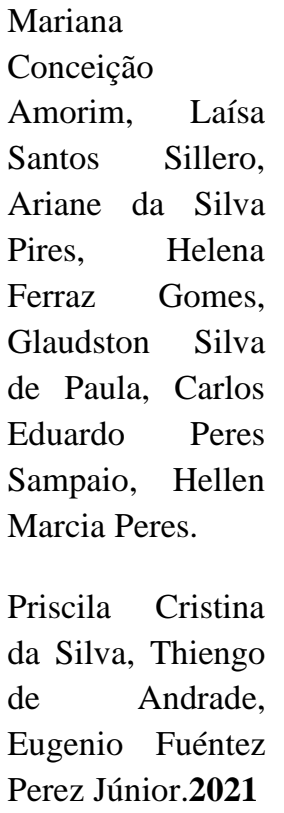 & 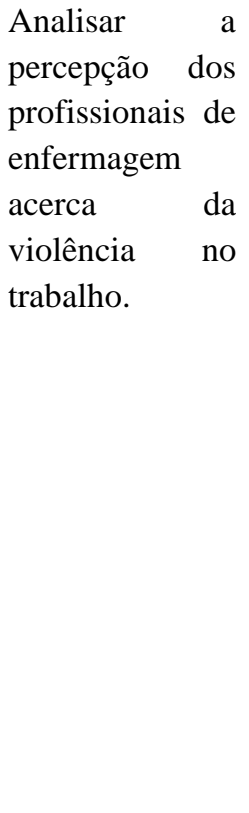 & $\begin{array}{l}\text { Estudo } \\
\text { qualitativo, } \\
\text { descritivo e } \\
\text { exploratório } \\
\text { realizado na } \\
\text { unidade do } \\
\text { plantão geral } \\
\text { de um hospital } \\
\text { público } \\
\text { situado no } \\
\text { Estado do Rio } \\
\text { de Janeiro. }\end{array}$ & $\begin{array}{l}\text { A violência no trabalho } \\
\text { apresenta diferentes facetas de } \\
\text { ordem física, psíquica e social. } \\
\text { Recomenda-se que outras } \\
\text { pesquisas sejam desenvolvidas, } \\
\text { como o estudo da violência em } \\
\text { diversos setores assistenciais em } \\
\text { diferentes níveis de atenção à } \\
\text { saúde. }\end{array}$ \\
\hline
\end{tabular}




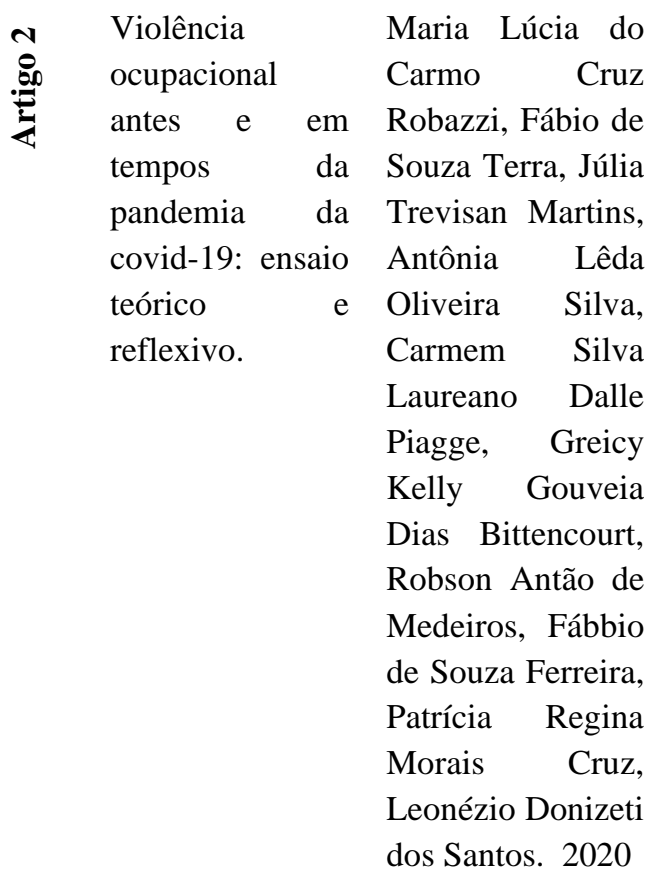

Reflexões

acerca

violência

ocupacional na

Enfermagem

tanto antes

como durante a

pandemia da

COVID-19.

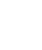

Trata-se de um a ensaio teórico e reflexivo.

Espera-se que esse texto sirva como um alerta aos próprios trabalhadores e gestores, possibilitando-se pensar formas de minimização desse indesejável fenômeno que é a violência.

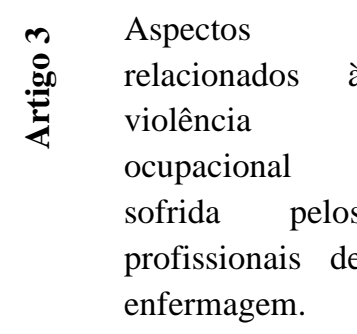

Dayane da Silva

à Tavares,

Alessandra

Baraúna da Silva,

Anne Beatriz

Moreira da Silva

Christian Catique

Barbosa,

Giovanna da Silva

Souza, Damara

Raína

Lozano

Videira, Ellen

Juliany Duarte

Prestes, Mayara

Greyce Lopes

Mendonça,

Silvana Nunes

Figueiredo. 2020
Pesquisar sobre a violência ocupacional, identificando seus devidos fatores, cuja esta é sofrida pelos profissionais de enfermagem em seu ambiente laboral.
Trata-se de um estudo descritivo exploratório onde optou-se por métodos de Revisão Sistemática e Metanálise.
Evidencia que a violência no ambiente laboral do profissional de enfermagem é algo recorrente, porém, dificilmente denunciado, o que faz com que essa problemática seja pouco estudada, sendo necessária a criação de um protocolo tanto para prevenção do problema quanto para sua solução. 


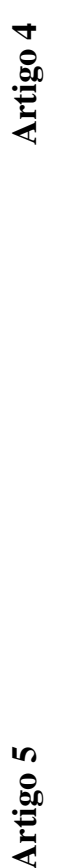

Violência

ocupacional

equipe

enfermagem:

prevalência

fatores

associados
Sirlene Aparecida

na Scarpin Tsukamot

de o, Maria José

Quina Galdino,

e Maria Lucia do

Carmo

Cruz Robazzi,

Renata Perfeito

Hirata Soares,

Maria do Carmo

Fernandez

Lourenço Haddad,

Júlia Trevisan

Martins. 2019

\begin{abstract}
Agressão verbal
no trabalho da

Enfermagem na

área hospitalar.
\end{abstract}

Ribeiro, Marcos
Letícia de Lima

Trindade, Suellen

Tainá

Elisangela

Ribeiro,

Argenta Zanatta

Carine

Vendurscolo,

Daiane Dal Pai.

2019
Identificar a
prevalência e os
fatores

associados

violência

ocupacional na

equipe

enfermagem.

de

e trat$$
\text { enfermagem }
$$

de um hospital universitário da Região Sul do Brasil.

Analisar

episódios

violência

trabalho,

forma

agressão verbal,

contra

profissionais de

enfermagem em

um cenário

hospitalar. os

de

no

na

de

, qua

.

Trata-se de um

estudo

realizado com

uma amostra

de 242

rabalhadores

e

o

1

transversal

A equipe de enfermagem foi vítima de diferentes tipos de violência no trabalho e associaram-se a ela, principalmente, os fatores ocupacionais, como testemunhar a violência ocupacional.

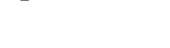

Trata-se de um

Observou-se elevada incidência estudo misto, de agressão verbal contra a que utilizou a enfermagem no cenário e abordagem indícios da banalização do qualitativa e fenômeno, o que impacta na qualidade da assistência frente ao desafio de instituir a cultura de paz e identificar, prevenir e tratar o problema.

Pesquisa Os enfermeiros percebem o qualitativa, racismo institucional de forma descritiva e distorcida, com reduzido exploratória, conhecimento e provimento de com amostra ações voltadas à saúde da constituída por nove enfermeiros da população negra. Porém, ressaltam meios educativos para rede de atenção à Lasta. 2019 saúde de um

município do

litoral norte do

Rio Grande do

Sul. Método

de análise de conteúdo. 


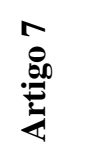

Delineamento da

violência sofrida

pela equipe de

enfermagem na

emergência.
Ana Paula da

Fonseca da Costa

Fernandes, Joanir

Pereira Passos.

2018
Trata-se de recorte

estudo qualitativo, descritivo, utilizando técnica análise conteúdo, po meio entrevistas com 24 profissionais que trabalham na emergência de um hospital público, no Rio de Janeiro. 24 de Os achados expressam uma de realidade local a ser transformada, visando à melhoria das condições de trabalho a equipe de enfermagem e da qualidade assistencial.

\section{or} de

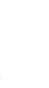




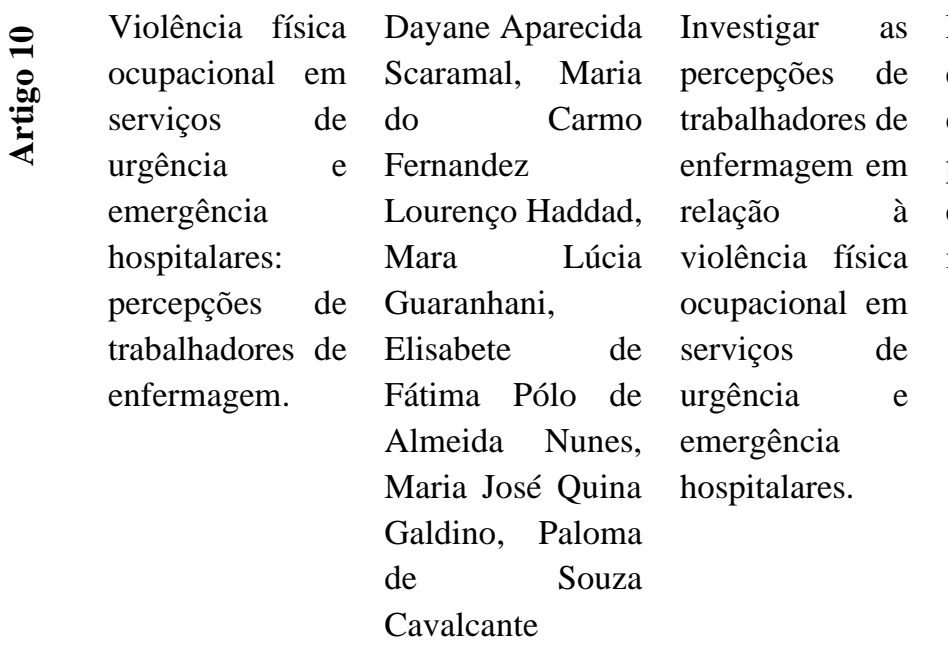

Pissinati. 2017

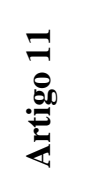

\begin{tabular}{lrl} 
Violência no & Maiara \\
trabalho da & \multicolumn{2}{l}{ Bordignon, Mari } \\
enfermagem: um & Inês Monteiro \\
olhar às & 2016 & \\
consequências. & &
\end{tabular}

$\mathrm{R}$

das

consequências

da violência no

trabalho

experienciada

por

profissionais de enfermagem
Estudo

qualitativo

desenvolvido

por meio de 16

entrevistas

individuais.
A compreensão da violência física ocupacional sob a perspectiva dos diferentes atores revelou sua complexidade e a importância do desenvolvimento de ações não apenas por parte dos profissionais de enfermagem, mas pelas equipes multiprofissionais $\quad \mathrm{e}$ intersetoriais, visando à prevenção e ao enfrentamento da violência ocupacional.

$\begin{array}{lrl}\begin{array}{l}\text { Violência } \\ \text { trabalho }\end{array} & \text { no } & \text { Nayanny } \\ \text { equipe } & \text { de } & \text { Almeida. 2016 } \\ \text { enfermagem: } & & \\ \text { prevalência } & \text { e } & \\ \text { fatores } & & \\ \text { associados nas } & \\ \text { emergências de } & \text { de } \\ \text { referência para } \\ \text { causas externas. }\end{array}$

Caracterizar a de prevalência, a tipologia e os fatores associados violência interpessoal no local de trabalho, contra profissionais de enfermagem da assistência hospitalar, de emergência em hospitais de referência para causas externas em Fortaleza, Ceará.

Trata-se de um artigo de reflexão que contou com o auxílio de publicações relacionadas a esta proposta, sobretudo de pesquisas realizadas no Brasil e em outros países.

Trata-se de um estudo de corte transversal analítico com abordagem quantitativa.
Aponta-se para o potencial nocivo e oneroso deste fenômeno, por ser capaz de ocasionar sofrimento, adoecimento, afastamentos do trabalho. e até a morte. Esta reflexão sensibiliza, ainda mais, para a importância de ambientes de trabalho seguros e em condições adequadas na área da saúde.

Para implementação de medidas e intervenções voltadas para a saúde do trabalhador, devem ser considerados não somente os elementos intrinsecamente ligados ao processo de trabalho, mas também os elementos externos; faz-se necessário um conjunto de ações que englobem os profissionais de saúde, administradores e gestores, políticas públicas, fatores económicos, sociais e culturais. 


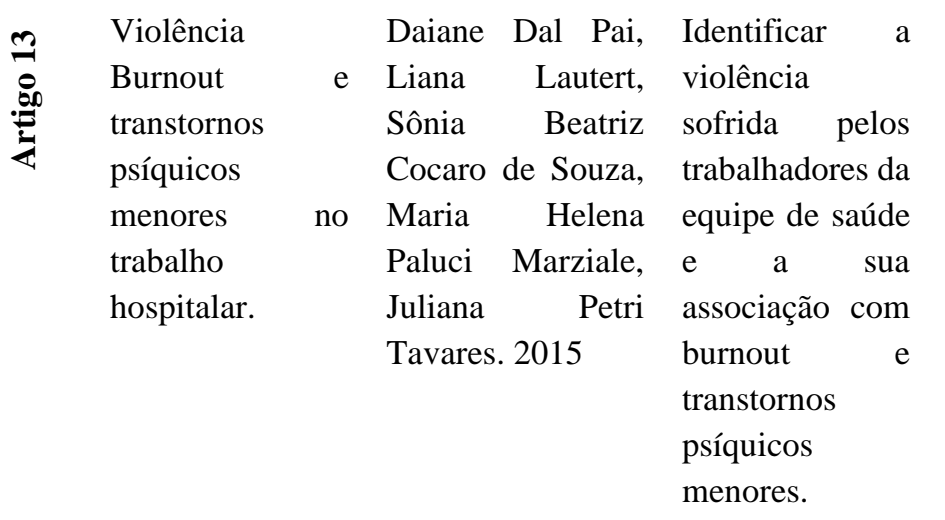

$\begin{array}{llr}\text { Estudo de } & \text { Os trabalhadores de saúde } \\ \text { delineamento } & \text { sofrem violência em seu } \\ \text { transversal. } & \text { ambiente de trabalho e a essa } \\ & \text { exposição, associam-se os } \\ & \text { sintomas de burnout e } \\ & \text { transtornos psíquicos menores. }\end{array}$

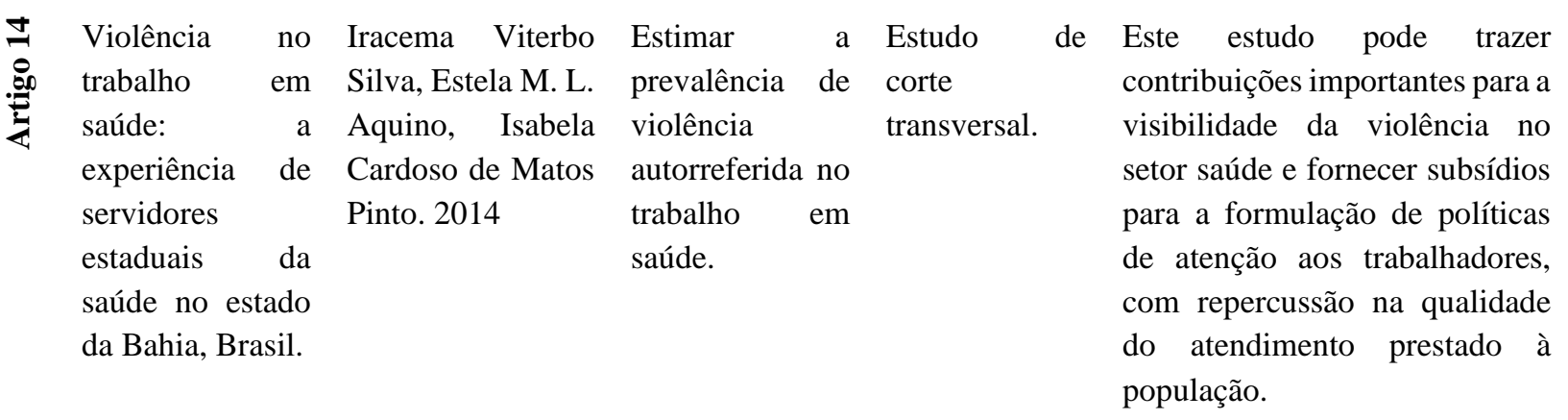

Fonte: Autores (2021).

A partir da leitura dos artigos, foi possível a identificação de variáveis que foram agrupadas em três categorias, são elas: Os tipos e os motivos mais comuns relacionados à violência entre a equipe de enfermagem, a violência ocupacional entre os profissionais de enfermagem, e ainda as consequências decorrentes da violência ocupacional.

\section{Os tipos e os motivos mais comuns relacionados à violência entre a equipe de enfermagem}

No ambiente de trabalho, as formas de violência física, considerada a mais comum, se configuram pelas investidas de ataques corporais como chutar, morder ou atirar algum objeto; o abuso verbal em que o agressor pratica uma fala descomedida e com excesso transmitindo sentimento de humilhação e desrespeito à vítima; assédio sexual representado pelo abuso sexual que é visto como um ato indesejado, inconsequente e fortuito (Ministério do Trabalho, 2004).

Almeida (2016) afirma que a violência no trabalho pode ser física, que se conceitua pelo uso de força física contra outro indivíduo ou grupo, que resulta em prejuízo físico, sexual ou psicológico; ou psicológica, utilizando forma intencional de poder, envolvendo ameaça de força física, apresentando quatro subtipos: agressão verbal, assédio moral, assédio sexual e discriminação racial.

Segundo Almeida (2016) a agressão verbal, faz parte da violência psicológica, sendo identificada por uma fala nítida ou implícita que remete ofensa, depreciação pessoal ou profissional, bem como sentimento de humilhação à vítima. Na maioria das vezes, o agressor utiliza um tom afrontoso, intimidação, supremacia e acusações, utilizando-se de palavras pouco cordiais.

O assédio moral define-se como comportamento hostil que causa ofensa, que se repete por várias vezes e por tempo indefinido, causando prejuízos psicológicos, por meio de ações maliciosas a uma pessoa ou a determinada camada de trabalhadores (Almeida, 2016). Sendo que "um número significativo de enfermeiros referenciou que foi vítima de assédio moral, em seu ambiente de trabalho, de forma repetitiva e sistemática" (Silva et al., 2015, p. 10).

Lucena et al. (2019) ensina que existem formas de classificar o assédio moral: a horizontal, que envolve profissionais 
de um mesmo nível de cargos; "a vertical, que se subdivide em vertical descendente (quando a agressão advém do superior contra o subordinado); e vertical ascendente (em que o subordinado agride o superior)"; e também a forma mista, caracterizando a agressão entre colegas do mesmo nível e chefes (p. 2).

Quanto ao assédio sexual, a pessoa envolvida passa por constrangimento, humilhação e intimidação decorrente de postura de natureza sexual, inconveniente e não recíproca5. Em diversas situações, a vítima sentindo-se acuada passa a se manter isolada de outros pares e evita falar sobre o assunto, por acreditar que será negligenciada pelo grupo de trabalho (Almeida, 2016).

Além disso, a incerteza em relação à aplicabilidade da justiça leva a crer que essas ocorrências improvavelmente chegam ao tribunal e o processo se transforma em uma investigação complementar à violência (Almeida, 2016).

Para Rosa, Christovão, Furlin e Lasta (2019) a discriminação racial também faz parte dos tipos de violência e o racismo institucional ocorre dentro das equipes de saúde. As questões sobre raça, cor e etnia ainda são pouco discutidas e a formação continuada incluindo a temática ainda tem pouca sustentação.

Barreto e Heloani (2015) sustenta que "a discriminação racial é tão severa quanto o preconceito em si, apesar das inúmeras campanhas por igualdade de direitos e contra as práticas racistas" (p. 5).

Fernandes e Passos (2018) diz que o enfermeiro, enquanto indivíduo e ser que atua no ambiente hospitalar, pode intervir e ser influenciado pela sociedade, reproduzindo a discriminação racial em suas ações.

No estudo de Almeida (2016), foi identificada a ausência de registros de episódios da violência no local de trabalho e também verificou-se uma estatística pouco considerada acerca da advertência dos casos de agressão verbal entre os trabalhadores da enfermagem que passaram por essa categoria de violência (p. 61).

A prevalência de assédio sexual, tendo como autores os colegas de trabalho foi de 67,7\%, seguidos dos chefes/supervisores com percentual de 22,6\%, e ocorreu duas vezes ou mais no período. Sobre o sexo do assediador, a maioria era do sexo masculino (71\%), onde as vítimas eram de sexos opostos. 13,3\% dos participantes referiram que o assédio sexual foi relatado ao chefe imediato ou à diretoria de enfermagem, e nenhum deles soube informar se houve consequências para $o$ assediador (Almeida, 2016, p. 67).

Ainda, 5,78\% referiram outros tipos de violência ocupacional, como a psicológica e o assédio moral. Tendo alta prevalência e graves consequências para os trabalhadores assediados e para o ambiente de trabalho. A maior prevalência de assédio moral entre os enfermeiros pode ser interpretada pelo uso indevido do poder conferido a alguns profissionais devido à sua posição hierárquica na estrutura organizacional do serviço (Almeida, 2016).

Em pesquisa realizada pelo Conselho Federal de Enfermagem (COFEN) com os profissionais de Enfermagem do Brasil, encontrou-se prevalência de violência no trabalho de 33,6\% para os enfermeiros e 27,3\% para os técnicos de Enfermagem (Almeida, 2016). A discriminação de gênero e o retalhamento psicológico foram as formas de violência mais observadas entre os profissionais (Almeida, 2016).

Rosa et al. (2019) assevera que muitos são os motivos que contribuem para que a violência aconteça entre os profissionais da enfermagem. Dentre eles estão a sobrecarga das atividades diárias, a falta de comunicação interna e a ausência de reconhecimento do trabalho prestado. Ademais, a falta de confiança e o mau relacionamento no interior da equipe, também corroboram para as reações negativas capazes de desencadear a violência ocupacional (Rosa et al., 2019).

Arcanjo, Chistovam, Braga e Silvino (2018) destacou ainda, a "fadiga, tensão, perda de controle sobre o trabalho", impacto das escalas noturnas, horas a mais trabalhadas, a subordinação, entre outros. "O excesso de responsabilidade e o acúmulo de função foram destacados" (p. 355).

Para Rosa et al. (2019) o fator gênero quando associado aos motivos colaborativos à violência tem um peso maior, 
visto que as mulheres exercem atividades domésticas e trabalham fora necessitando mais esforço físico e mental, ocasionando esgotamento físico.

De acordo com Dal Pai, Lautert, Souza, Marziale e Tavares (2015), um estudo profundo demonstrou "a exposição de enfermeiras à violência de gênero, devido o excesso de trabalho". Em nível relacional, a disputa por cargos de chefia, a falha na comunicação e as relações sociais entre pares, elevam os índices de violência no trabalho (Trindade, Ribeiro, Zanatta, Vendurscolo e Dal Pai, 2019).

Dal Pai, Lautert, Souza, Marziale e Tavares (2015), leciona que os trabalhadores menos providos economicamente, a gestão hospitalar pouco eficiente e os fatores humanos representados por comportamentos eticamente desestruturados, favorecem o acontecimento da violência ocupacional.

Conforme Almeida (2016) as degenerações emocionais e psíquicas são incalculáveis, resultando "desmotivação, perda de confiança, baixa autoestima, depressão, raiva, ansiedade e irritabilidade”. Os eventos mais severos têm potencial para deflagrar acidente ocupacional, que podem alcançar riscos extremos como invalidez e suicídio (p. 43).

Outros aspectos como espaço inadequado, intransigência racial, desigualdade de oportunidades e relações interpessoais fragilizadas, marcadas pelo individualismo e o comportamento desrespeitoso, também assessoram a violência no ambiente de trabalho (Almeida, 2016).

Robazzi, Terra, Martins e Silva (2020), diz que durante a pandemia da COVID-19, a enfermagem se encontra mais exposta a situações de violência, sejam por pacientes/cuidadores ou trabalhadores. No Brasil, um ato dessa violência aconteceu com enfermeiros que estavam presentes em uma homenagem silenciosa aos colegas que morreram lutando contra a COVID19. Os estressores ocupacionais continuam presentes na assistência, como agressão física, verbal e assédio moral.

Neste momento de pandemia foi verificada uma alta demanda de violência psicossocial, decorrente das condições de trabalho fragilizadas, pelo uso de equipamentos de proteção individual e pelo quantitativo de trabalhadores na linha de frente de atendimento ao COVID-19 (Robazzi, Terra, Martins e Silva 2020).

\section{Violência ocupacional entre os profissionais de enfermagem}

Em seu processo laboral, o profissional de enfermagem relaciona-se com seus pacientes, em vista do cuidado prestado, e com os colegas, devido à continuidade do cuidado. Sendo que o relacionamento interpessoal ruim no trabalho vem associado expressivamente à violência física (Tsukamoto et al. 2019).

Os profissionais da enfermagem enxergam a violência ocupacional como algo de grande preocupação e que não recebe estímulos da instituição para o relato e tomada de medidas mais severas. Sustentam também que a violência pode resultar em malefício para o desenvolvimento físico, mental, espiritual, oral ou social (Tsukamoto et al. 2019).

No Brasil e em outros países, ocorre a violência na área da saúde representada por aproximadamente um quarto do total de casos violentos no trabalho, sendo rotineira entre os profissionais da enfermagem. De acordo com o Conselho Regional de Enfermagem do Estado de São Paulo (COREN-SP) em 2015, o Brasil aponta números relevantes em relação a esta problemática. Nessa investigação que contou com a participação de 8.332 profissionais da enfermagem, 74\% afirmaram ter sofrido violência laboral (Bordignon e Monteiro, 2016).

Em uma pesquisa de campo realizada junto a 679 servidores lotados no nível central e nas unidades de saúde da Secretaria da Saúde do Estado da Bahia (SESAB), localizados no Município de Salvador - Brasil, investigou-se sobre as espécies de violência (física, verbal, assédio sexual, discriminação e danos contra a propriedade pessoal) e constatou-se que $25,9 \%$ dos entrevistados referiram pelo menos uma destas modalidades, sendo mais frequente a agressão verbal (19,4\%), atingindo, especialmente, os auxiliares/técnicos em enfermagem (28\%) e os médicos (23,9\%). Em 66,6\% dos casos, a violência 
aconteceu por mais de duas vezes. Em seguida, aparece a discriminação (5,9\%), destacando-se a racial e a social. Os outros tipos de violência apresentaram percentuais abaixo de 4\%. Verificou-se também que, não houve muita diferença em relação à violência praticada contra homens ou mulheres. Enquanto para os homens a proporção foi de 23,3\%, entre as mulheres foi de 26,5\% (Fernandes \& Passos, 2018; Trindade, Ribeiro, Zanatta, Vendurscolo \& Dal Pai, 2019).

Em outro estudo realizado em dezembro de 2014, em dois hospitais psiquiátricos da rede pública de Belo Horizonte, Minas Gerais, Brasil, foi observado que os profissionais da enfermagem são mais acometidos pela violência física e verbal que outros profissionais. Em hospitais psiquiátricos essas taxas são altíssimas, o que varia entre 1,7\% a 71,6\%, demonstrando que as características dos agressores acabam colaborando para o acontecimento desses atos violentos dentro do ambiente de trabalho. Os percentuais de violência física especificamente podem chegar a representar 17\% dos casos (Arcanjo, Chistovam, Braga \& Silvino, 2018; Tavares et al., 2021).

Estudo realizado no ano 2019, em um hospital escola da Região Sul do Brasil, com uma amostra de 242 indivíduos, demonstrou que a predominância de violência física no período foi de $20,2 \%$, dos quais $49 \%$ revelaram uma frequência de duas vezes ou mais no período. Em 6,2\% dos casos, envolveu arma branca ou de fogo e nas demais foi corpo a corpo. Quanto à autoria da violência, prevaleceram os pacientes e seus familiares $(63,3 \%)$, seguidos dos colegas de trabalho $(24,5 \%)$ e chefes ou supervisores (12,2\%). Sobre o sexo do agressor, a maioria era do masculino $(56,2 \%)$ e em 50\% dos casos, vítima e agressor eram de sexos opostos. Em apenas $8,5 \%$ dos casos, os participantes referiram que a violência física foi registrada em comunicados internos. Em 4,3\% a advertência verbal foi a consequência para o agressor, que foi de conhecimento da vítima (Tsukamoto et al., 2019).

Os dados sobre o abuso verbal no ano de 2019 foi de 59,1\%, dos quais 77,5\% revelaram a frequência de duas vezes ou mais no período. Em relação à autoria do abuso, prevaleceram os colegas de trabalho (38,4\%), seguido dos chefes/supervisores $(35,7 \%)$. Sobre o sexo do abusador, a maioria era do feminino $(82,5 \%)$ e em $69,9 \%$ dos casos, a vítima e o agressor eram do mesmo sexo. Em 17,4\% dos casos, referiu-se que o abuso verbal foi registrado administrativamente (ouvidoria, prontuário, livro de ocorrência) ou na polícia. Em 3,6\% houve consequências para o abusador que foram de conhecimento da vítima, como advertência verbal $(2,2 \%)$ por escrito $(0,7 \%)$ ou reunião administrativa $(0,7 \%)($ Tsukamoto et al., 2019).

Ao estudar o assédio moral no trabalho no setor saúde no Rio de Janeiro, a equipe de enfermagem relatou que as formas de violência identificadas foram: agressões verbais $(93,3 \%)$, assédio moral (30\%), competição entre colegas (23\%), agressões físicas $(16,7 \%)$, roubos $(13,3 \%)$, discriminação social (3,3\%) e maus-tratos (3,3\%) (Almeida, 2016).

No serviço de emergência em Natal, no Rio Grande do Norte, a prevalência de violência ocupacional foi de 74,92\% entre enfermeiros e 78,95\% entre os técnicos e auxiliares de Enfermagem. Sendo 70,20\% agressão verbal, 24,08\% assédio moral, 6,12\% agressão física e 3,67\% assédio sexual (Almeida, 2016).

\section{Consequências decorrentes da violência ocupacional}

Ao passar por episódio de violência ocupacional, o trabalhador passa por frustração e conflito interior, diminuindo o seu senso de comprometimento com a organização ao qual está inserido, reduzindo ainda a qualidade na realização de atividades laborais (Tsukamoto et al., 2019; Bordignon \& Monteiro, 2016).

Dal Pai, Lautert, Souza, Marziale e Tavares (2015) afirma que ao profissional que sofre violência no trabalho, repercute uma serie de danos físicos, psicológicos e sociais, dentre eles o burnout e os transtornos psíquicos menores, afetando sua integridade física e os seus direitos como pessoa, ferindo a moral e a dignidade.

O burnout trata-se de uma síndrome predominante em trabalhadores da área da saúde que se caracteriza por "exaustão 
emocional" elevada e impessoalidade quanto à realização de atividades laborais. As consequências negativas da violência em relação à saúde do trabalhador e o amparo prestado têm sido revelados através de "sintomas de estresse, baixa autoestima e desmotivação das vítimas" (Arcanjo et al., 2018). Sendo que esses sintomas também se relacionam ao burnout.

Nesse sentido, os transtornos psíquicos menores estabelecem relações com as vítimas de violência no trabalho, que ao ser agredido desenvolve sintomas como "ansiedade, insônia, tristeza, fadiga, esqueci mento, dificuldade de concentração, irritabilidade, queixas somáticas e neurastenia". Segundo a literatura, esses sintomas não se enquadram nos psicóticos e sim nos psiquiátricos" (Arcanjo et al., 2018).

Quase todos os profissionais que tiveram envolvimento com a violência, no uso de suas funções, sentiram um incômodo preocupante que resultaram em "memórias perturbadoras" consecutivas, pensamentos ou recordação do ataque de agressão. Vivencia-se em experimentos realizados no Brasil que as ações ou fatos observados no local de trabalho ocasionam, na maioria das vezes, "sofrimento, dor, adoecimento, desgaste emocional, sofrimento mental e/ou físico, o que desencadeia incapacidade, absenteísmo e aposentadoria precoce" (Trindade et al., 2019).

Os elementos que fazem parte do ambiente de trabalho, representados pelo vínculo empregatício, os direitos trabalhistas, a remuneração, a infraestrutura, a burocracia exagerada e a desvalorização do profissional podem acarretar postura e sentimentos de negação, declínio, resistência, degradação física, emocional e desolação. Ademais, a violência perturba a integridade física, moral, social e emocional prejudicando a vida do trabalhador” (Trindade et al., 2019).

A violência no ambiente laboral associa-se diretamente a agravos como desenvolvimento de enfermidades, dentre elas, "depressão, ansiedade e distúrbios do estresse pós-traumático", bem como à vergonha por ter passado por tal situação, sentimentos de raiva, angústia, conflito interior, desordem de pensamentos, menosprezo pelos seus serviços prestados aos pacientes (Arcanjo et al., 2018; Bordignon \& Monteiro, 2016).

Quanto às mais variadas reações vivenciadas por questões relacionadas à violência no trabalho, foram relatadas algumas situações em que a vítima buscou manter a calma a fim de não ocasionar mais prejuízos para si mesmo, tentando preservar a relação de laboro com a vida pessoal. No intuito de se resguardar e garantir a autodefesa, esses colaboradores alargaram mecanismos por meio de distanciamento afetivo, exclusão e comportamentos hostis com pacientes e também com outros colegas de trabalho (Robazzi et al., 2020). Sendo que o enfermeiro é considerado o profissional que mais passa por agressões verbais, tais como: "ser tratado com desprezo, ignorado, desdém, tratamentos inapropriados, olhares hostis, insultos, observações desrespeitosas, chamado de incompetente ou estúpido" (Pedro, Silva, Lopes, Oliveira e Tonini, 2017).

A questão da violência também projeta consequências negativas à instituição como restrição da capacidade e produtividade dos trabalhadores, exaustão, licenças e constante rodízio dos profissionais (Tavares et al., 2021). No ambiente hospitalar, a probabilidade de violência ocupacional é maior entre os profissionais de enfermagem que prestam serviços de urgência e emergência (Scaramal et al., 2017). Quanto à comunidade, a violência no trabalho pode "impactar economicamente nos cuidados de saúde", devido à complicada reabilitação e restituição das vítimas (Almeida, 2016).

\section{Considerações Finais}

Foi possível observar que a violência ocupacional entre a equipe de enfermagem não se comporta como um fato isolado e acontece com muita frequência.

A violência física é a mais comum, em seguida, o abuso verbal. Outra forma de violência muito relatada é a sexual, ocasionada por colegas de trabalho, a maioria do sexo masculino, onde as vítimas são as mulheres/colegas. O assédio moral acontece mais entre os enfermeiros e muitas vezes é interpretado pelo uso indevido do poder, devido a sua posição hierárquica.

Outra maneira que o profissional de enfermagem vivencia a violência é por pacientes, pois convivem com pessoas em 
vários estados de saúde e com os seus familiares. Pessoas geralmente contrariadas pelo processo ao qual estão passando, pela prestação dos serviços de saúde precários, e com isso podem acabar se comportando de forma violenta com o trabalhador. Sendo o enfermeiro o profissional da saúde mais atingido.

Os motivos mais reportados que levam a violência ocupacional no ambiente hospitalar entre os profissionais de enfermagem são, a sobrecarga de atividades diárias, falta de comunicação interna ligada à gestão pouco eficiente, falta de reconhecimento do trabalho prestado, impacto das escalas noturnas, falta de ética no trabalho, espaço inadequado, fadiga, tensão, degenerações emocionais e psíquicas.

E essas violências levam os profissionais a sofrerem consequências, sendo as mais comuns: frustração, conflito interior, baixa qualidade na prestação dos serviços, bem como o pouco comprometimento com a Instituição. Burnout, desgaste emocional, sofrimento, adoecimento, absenteísmo e aposentadoria precoce. As Instituições de Saúde também são prejudicadas porque há um declínio na qualidade da assistência à saúde, que tem como fator determinante a satisfação e a produtividade de seus colaboradores.

As vítimas - profissionais de enfermagem, nessas situações previamente citadas se sentem desamparados e muitas vezes passam a se manterem isoladas dos outros colegas, evitando falar sobre o assunto. Preocupam-se com a incerteza da aplicabilidade da pena na justiça comum ou até mesmo na Instituição de Saúde, sentem medo de represália da Instituição, dos colegas e até mesmo de ser penalizada por uma situação que pode não ser comprovada e com isso, teme pela perda do emprego, mudança de setor e horário de trabalho não desejado.

Ademais, torna-se evidente que condutas de prevenção e controle da violência no trabalho foram objetos de estudo de poucas produções científicas pesquisadas.

Para futuros trabalhos sugerimos que tenha mais pesquisas sobre a temática com o foco em racismo institucional, raça, cor e etnia.

\section{Agradecimentos}

Nenhum trabalho como este é construído sem que, ao longo do caminho eu não tenha necessitado do auxílio de pessoas, livros e artigos que me ajudaram, das mais diversas formas, a concluir o estudo.

Inicialmente, quero expressar minha gratidão aos professores, que me passaram conhecimentos ao longo da jornada acadêmica. Em especial à Professora Mayara que me deu orientação e que com sua sabedoria me auxiliou até chegar ao caminho certo, o da efetivação do TCC.

Dedico esse trabalho a minha querida mãe Raimunda Nonata Saboia (in memorian), que não pode estar ao meu lado neste momento tão importante, mas que sempre torceu muito por mim.

Um profundo agradecimento precisa ser feito ao Professor Raimundo Nonato Alves e os amigos que me incentivaram quanto à escolha e desenvolvimento do tema, me dando total apoio quanto ao estudo levantado.

Finalmente, agradeço imensamente ao Criador, por haver ele escolhido escrever o livro do Universo com as letras das histórias de vida, dando assim, em minha insignificância, a maravilhosa oportunidade de compreender um pouco de sua admirável obra. E também por me dar sustentação e força para compreender os desafios enfrentados.

\section{Referências}

Almeida, N. R. (2016). Violência no trabalho na equipe de enfermagem: prevalência e fatores associados nas emergências de referência para causas externas. (Dissertação de Mestrado, Universidade Federal do Ceará, Faculdade de Medicina. Fortaleza, Brasil). Recuperado de http://www.repositorio.ufc.br/bitstream/riufc/21577/1/2016_dis_nralmeida.pdf. 
Amorim, M. C, Sillero, L. S, Pires, A. S., Gomes, H. F., Paula, G. S, Sampaio, C. E. P., Peres, E, M., Silva, P, C., Andrade, T., Perez Jr., E. F. Violência no trabalho na perspectiva de profissionais de enfermagem. Rev. Enferm. Atual In Derme, 95(34), e-021067.

Arcanjo, R. V. G., Chistovam, B. P., Braga, A. L. S., Silvino, Z. R. (2018). Gerenciamento dos riscos ocupacionais da enfermagem na atenção primária à saúde: estudo exploratório descritivo. Revista Online de Pesquisa, 10(2),351-357. doi:10.9789/2175-5361.2018.v10i231-357

Barreto, M. \& Heloani, R. (2015). Violência, saúde e trabalho: a intolerância e o assédio moral nas relações laborais. Serviço Social e Sociedade, 123. https://doi.org/10.1590/0101-6628.036

Bordignon, M. \& Monteiro, M. I. (2016). Violência no trabalho da enfermagem: um olhar às consequências. Revista Brasileira Enfermagem, 69(5). https://www.scielo.br/j/reben/a/VpGTh7yjX4bppdTkxScRc8p/?lang=pt.

Conselho Federal de Enfermagem. (2017). Resolução Cofen $n^{\circ}$ 0564/2017: Aprova o novo Código de Ética dos Profissionais de Enfermagem. Brasília, DF: Cofen.

Dal Pai, D., Lautert, L., Souza, S. B. C., Marziale, M. H. P., Tavares, J.P. (2015). Violência, burnout e transtornos psíquicos menores no trabalho hospitalar. Rev. Esc. Enferm. USP, 49(3). https://www.scielo.br/j/reeusp/a/LJtz8Ww9pqztDMTPH8tPtqG/?lang=pt.

Fernandes, A. P. F. C. \& Passos, J.P. (2018). Delineamento da violência sofrida pela equipe de enfermagem na emergência. Rev. Enferm. UERJ, 26, e26877. https://pesquisa.bvsalud.org/portal/resource/pt/biblio-969529.

Lucena, P. L. C., Costa, S. F. G., Batista, J. B. V., Araújo, E. L. M., Soares, C. C. D., Rolim, R. M. G. C. (2019). Testemunhas de assédio moral, na enfermagem: identificando características desse fenômeno, sentimentos e estratégias de enfrentamento. Rev. Min. Enfer., 23,e-1164. doi: 10.5935/1415-2762.20190012

Marconi, M. A. \& Lakatos, E.M. (2017). Fundamentos de metodologia científica. (8a. ed.) São Paulo: Atlas.

Ministério do Trabalho. (2004). Política Nacional de Saúde do Trabalhador. Brasília, DF: Ministério do Trabalho.

OMS. (2002). Relatório mundial sobre violência e saúde. Genebra: World Health Organization. (WHO or in portuguese: OMS)

Pedro, D. R. C., Silva, G. K. T., Lopes, A. P. A. T., Oliveira, J. L. C., Tonini, N. S. (2017). Violência ocupacional na equipe de enfermagem: análise à luz do conhecimento produzido. Saúde Debate Online, 41(113). https://www.scielo.br/j/sdeb/a/CyzkBDpLYbjgfpxrYzQyXyD/abstract/?lang=pt.

Robazzi, M. L. C., Terra, F. S., Martins, J. T., Silva, A. L.O. (2020). Violência ocupacional antes e em tempos da pandemia da covid-19: ensaio teórico e reflexivo. Braz. J. Hea, 3(6). https://www.brazilianjournals.com/index.php/BJHR/article/view/21872.

Rosa, L. G. F., Christovão, R. G., Furlin, M., Lasta, J. B. (2019). Percepções e ações dos enfermeiros em relação ao racismo institucional na saúde pública. Rev. Enferm. UFSM, 9(e-8). https://periodicos.ufsm.br/reufsm/article/view/31131/pdf.

Scaramal, D. A., Haddad, M. C. F. L., Guaranhani, M. L., Nunes, E. F. P. A., Galdino, M. J. Q., Pissinati, P. S. C. (2017). Violência física ocupacional em serviços de urgência e emergência hospitalares: percepções de trabalhadores de enfermagem. Rev. Min. Enferm., 21. http://reme.org.br/artigo/detalhes/1160.

Silva, A. F., Costa, S. F. G., Batista, P. S. S., Zaccara, A. A. L., Costa, I. C. P., Duarte, M. C. S. (2015). Assédio moral: estudo com enfermeiros da estratégia saúde da família. Revista de Pesquisa Cuidado é Fundamental Online, 7(1),1820-1831. doi:10.9789/2175-5361.2015.v7i1.1820-1831

Tavares, D. S., Silva, A. B., Silva, A. B. M., Barbosa, C. C., Souza, G. S., Videira, D. R. L., Prestes, E. J. D., Mendonça, M. G. L., Figueiredo, S.N. (2021). Aspectos relacionados à violência ocupacional sofrida pelos profissionais de enfermagem. Revista Eletrônica Acervo Saúde, 13(2), e5881. https://doi.org/10.25248/reas.e5881.2021

Trindade, L. L., Ribeiro, S. T., Zanatta, E. A., Vendurscolo, C., Dal Pai, D. (2019). Agressão verbal no trabalho da enfermagem na área hospitalar. Rev. Eletr. Enferm., 21. doi: https://doi.org/10.5216/ree.v21.54333

Tsukamoto, S. A. S., Galdino, M. J. Q., Robazzi, M. L. C. C., Ribeiro, R. P., Soares, M. H., Haddad, M. C. F. L., Martins, J. T. (2019). Violência ocupacional na equipe de enfermagem: prevalência e fatores associados. Acta Paul. https://www.scielo.br/j/ape/a/T6hqPLG7hR7SRQy4jNzM4vc/abstract/?lang=pt. 